\title{
Naltrexone vs. Nefazodone for Treatment of Alcohol Dependence A Placebo-Controlled Trial
}

Henry R. Kranzler, M.D., Vania Modesto-Lowe, M.D., M.P.H., and Jeffrey Van Kirk, J.D., M.S.

This study compared the effects of nefazodone, a serotonergic antidepressant, with the opioid antagonist naltrexone, and an inactive placebo in 183 alcoholdependent subjects receiving weekly relapse prevention psychotherapy. Following a single-blind, placebo lead-in period, subjects were randomly assigned to receive study medication, which they took under double-blind conditions for 11 weeks. Naltrexone treatment was associated with significantly more adverse neuropsychiatric and gastrointestinal effects, poorer compliance, and a greater rate of treatment attrition. There were no reliable betweengroup differences in drinking behavior. These results indicate that nefazodone is not efficacious for treatment of alcohol dependence. Furthermore, the clinical utility of naltrexone seems to be limited by its adverse effects, a finding that has important implications for efforts to develop medications to treat alcohol dependence.

[Neuropsychopharmacology 22:493-503, 2000] (C) 2000 American College of Neuropsychopharmacology. Published by Elsevier Science Inc.
KEY WORDS: Naltrexone; Nefazodone; Alcohol dependence; Alcoholism; Randomized control trial; Alcohol treatment

Psychosocial interventions, such as psychotherapy and referral to self-help groups (e.g., Alcoholics Anonymous), are the standard treatments for alcohol dependence. However, the past decade has witnessed renewed interest in medications to treat alcoholism (Kranzler and Jaffe 1998; Litten and Allen 1998). The most intensively studied pharmacological treatments for alcohol dependence include opioid antagonists, serotonergic agonists, and acamprosate (Kranzler and Jaffe 1998; Litten and Allen 1998).

Evidence supporting a role for the opioid system in alcohol dependence includes lower basal plasma and

From the Alcohol Research Center, Department of Psychiatry, University of Connecticut School of Medicine, Farmington, CT.

Address correspondence to: Henry R. Kranzler, M.D., Department of Psychiatry, MC2103, University of Connecticut Health Center, Farmington, CT 06030-2103.

Received June 16, 1999; revised September 29, 1999; accepted October 8, 1999 cerebrospinal fluid levels of $\beta$-endorphin in alcoholics as compared with controls (Aguirre et al. 1990; Genazzani et al. 1981). Furthermore, unaffected adult children of alcoholics have basal levels of $\beta$-endorphin comparable to those of abstinent alcoholics and significantly lower than those of unaffected adults without a parental history of alcoholism (Gianoulakis et al. 1989, 1996). When given alcohol, adult children of alcoholics also showed a significantly greater increase (i.e., a "normalization") of $\beta$-endorphin levels (Gianoulakis et al. 1989, 1996).

Two double-blind placebo-controlled trials of the opioid antagonist naltrexone (NTX) showed it to decrease risk of relapse to heavy drinking in alcoholics (Volpicelli et al. 1992; O'Malley et al. 1992). These were the basis for approval of the drug by the U.S. Food and Drug Administration for the treatment of alcohol dependence. Subsequently, Oslin et al. (1997) found that NTX was superior to placebo in reducing the risk of relapse in a study of older veterans. However, Volpicelli et al. (1997) found that NTX was superior to placebo (PLA) only among alcoholics who were highly compli- 
ant with study visits and medication. Hersh et al. (1998) failed to show an advantage for NTX over PLA on measures of substance use or craving among subjects with co-morbid alcohol and cocaine use disorders. In a preliminary study of a sustained-release preparation of NTX, Kranzler et al. (1998) found that the active formulation was superior to PLA in reducing the frequency of heavy drinking.

The indoleamine neurotransmitter serotonin (5-HT) also seems to play a role in the pathophysiology of alcohol dependence (Gorelick 1989; Roy et al. 1990). Compared to controls, alcoholics have low CSF levels of 5-hydroxyindoleacetic acid (5-HIAA), the major metabolite of 5-HT (Gorelick 1989; Roy et al. 1990). Furthermore, an inverse relationship between CSF 5-HIAA levels and the time elapsed since alcohol was last consumed has been observed in alcoholics (Banki 1981). These findings suggest that drinking in alcoholics may serve to increase low 5-HT activity.

However, studies of the effect of serotonergic medications on human drinking behavior have yielded mixed results. The selective serotonin reuptake inhibitors (SSRIs) zimelidine, citalopram, viqualine, and fluoxetine were shown to produce modest decreases in alcohol consumption in nondepressed heavy drinkers (Naranjo et al. 1984, 1987, 1989, 1990). However, when fluvoxamine was combined with cognitive-behavioral therapy to treat alcohol dependence, the medication was poorly tolerated and seemed to be unsuitable for use among patients with this disorder (Kranzler et al. 1993).

Of the SSRIs, fluoxetine's effects on human alcohol consumption have been most studied. Among alcoholics given access to alcohol on a research ward, fluoxetine reduced alcohol consumption by $14 \%$ during the first week, a significant advantage over PLA. The effect, however, did not persist (Gorelick and Paredes 1992). Naranjo et al. (1990) found that fluoxetine $60 \mathrm{mg} /$ day decreased daily alcohol consumption by $17 \%$ from baseline in a group of early-stage problem drinkers, an effect that was not observed with fluoxetine $40 \mathrm{mg}$ /day or PLA. Subsequently, Naranjo et al. (1994) found that, although fluoxetine $60 \mathrm{mg}$ /day reduced the desire for alcohol, both in an experimental bar setting and when compared with PLA in an outpatient trial, it did not significantly reduce alcohol consumption. Using a crossover design, Gerra et al. (1992) compared the effects of fluoxetine $40 \mathrm{mg}$ /day, acamprosate, and PLA for treatment of alcoholism. These investigators found that although both active medications were superior to PLA in reducing the number of drinks consumed, the effect of fluoxetine was significant only among patients with a parental history of alcoholism.

Kranzler et al. (1995) found that fluoxetine treatment in conjunction with cognitive-behavioral psychotherapy in ambulatory alcoholics did not decrease drinking more than PLA. A similar lack of effects was observed when a variety of other variables, including family history of alcoholism, were examined in combination with medication treatment. Similarly, Kabel and Petty (1996) showed no effect of fluoxetine, compared with PLA, among alcoholic veterans.

We chose to study nefazodone (NEF) in light of the variable results from studies of SSRI treatment of alcohol dependence. Although NEF has a moderate inhibitory effect on reuptake of serotonin and norepinephrine, it potently and selectively blocks the postsynaptic $5-\mathrm{HT}_{2}$ receptor (Taylor et al. 1995). Based on preclinical findings implicating this receptor in alcohol drinking behavior (Meert et al. 1991; Myers et al. 1993), we hypothesized that the potent activity of NEF at the $5-\mathrm{HT}_{2}$ receptor would enhance the serotonin reuptake inhibiting effect of the drug. Consequently, the present study compared the effects of NTX, NEF, and an inactive PLA on risk and severity of relapse in alcohol-dependent subjects.

\section{METHODS}

\section{Subjects}

One hundred ninety-four subjects with DSM-III-R alcohol dependence (American Psychiatric Association 1987) were recruited through advertisements in local news media and referrals from area clinicians. The recruitment procedure and the study protocol were approved by the Institutional Review Board of the University of Connecticut Health Center. All subjects gave written, informed consent before participation.

Inclusion/Exclusion Criteria. Subjects were included in the study if they: (1) expressed a desire to maintain abstinence from alcohol for the 12-week treatment period; (2) were willing to be randomly assigned to one of the treatment conditions and to receive weekly counseling; (3) were 18 to 60 years old; (4) were abstinent from alcohol for at least 3 days before the baseline research assessment (as evidenced by self-report and two breath alcohol measurements); (5) were able to read English and complete study evaluations; and (6) if female, lacked reproductive potential. Subjects were excluded if they: (1) were homeless; (2) were currently dependent on a psychoactive substance other than alcohol or nicotine; (3) had a past diagnosis of opioid dependence; (4) regularly used psychoactive medications or disulfiram; (5) were currently suicidal, manic, or psychotic; (6) had significant, uncontrolled medical illness; or (7) were abstinent longer than 28 days before randomization. Psychiatric disorders that did not require acute intervention, such as mild major depression, were not exclusionary. When disorders that were potentially amenable to pharmacotherapy were identified, subjects 
were informed of the availability of a potentially effective treatment and were given the option of receiving such treatment, rather than participating in the study.

A total of 183 subjects completed the 1-week PLA lead-in period and were randomly assigned to doubleblind medication treatment. Table 1 shows demographic and clinical features of subjects who were randomized to receive double-blind study medication. The following prevalence of current psychiatric disorders was observed among randomized subjects: dysthymic disorder, $12.0 \%$; antisocial personality disorder, $8.7 \%$; major depressive disorder, $5.5 \%$; social phobia, $4.4 \%$; generalized anxiety disorder, $4.4 \%$; panic disorder, $3.8 \%$; agoraphobia, $2.2 \%$; and simple phobia, $1.1 \%$. The prevalence of these diagnoses did not differ significantly by Medication Group ( $p$ 's all $>0.10$ ).

\section{Medical and Laboratory Assessments}

Following an initial screening interview by a research nurse, each subject underwent a battery of clinical assessments, including physical examination, urinalysis, urine toxicology, serum chemistry panel [(including $\gamma$ glutamyltranspeptidase (GGTP)], and, for women who were neither postmenopausal nor surgically sterile, a serum pregnancy test. The GGTP level was repeated at the end of the 12-week treatment phase, thereby providing an objective measure of alcohol consumption during treatment.

\section{Research Assessments}

Data on demographics, family history of alcoholism, medical history, psychiatric diagnoses, and substance use history were collected at entry into the study. Parallel assessments of alcohol consumption and conse- quences were conducted at baseline and at the end of the 12-week treatment phase. At each weekly visit, breath alcohol was measured and information was obtained on treatment received outside of the study protocol (including AA meeting attendance), and adverse events. Weekly urine samples were examined for the presence of riboflavin (Del Boca et al. 1996). At monthly intervals during the treatment period, urine was also tested for the presence of drugs of abuse. All assessments were performed by staff members who were blind to treatment status.

For subjects who did not complete the active treatment, an endpoint assessment was performed, either at the time of study discontinuation or as soon thereafter as possible. All but one subject $(0.5 \%)$ provided information on drinking behavior during the Randomized Treatment Period.

Demographics and Family History. Using a self-report questionnaire, data were collected on family psychiatric history, socioeconomic status, marital status, educational and occupational information, and use of treatment services.

Psychiatric Diagnosis and Symptoms. The Structured Clinical Interview for DSM-III-R (SCID; Spitzer et al. 1992) was used to classify subjects according to the presence or absence of DSM-III-R (American Psychiatric Association 1987) disorders. The Beck Depression Inventory (BDI; Beck et al. 1961) provided a measure of the number and severity of depressive symptoms.

Substance Use History, Patterns, and Severity. The TimeLine Follow-Back Assessment method (TLFB; Sobell et al. 1980) was used to estimate alcohol consumption. The TLFB has good test-retest reliability and validity when used by trained interviewers (Sobell et al. 1979, 1986). The Typology Questionnaire (Hesselbrock et al. 1983) pro-

Table 1. Pretreatment Demographic and Clinical Features by Medication Group

\begin{tabular}{|c|c|c|c|c|c|}
\hline & Naltrexone $(n=61)$ & Nefazodone $(n=59)$ & Placebo $(n=63)$ & Test Statistic & $p$ \\
\hline \multicolumn{6}{|l|}{ Demographics: } \\
\hline Gender ( $\%$ male $)$ & 80.3 & 78.0 & 74.6 & $\chi^{2}=0.59$ & .74 \\
\hline Race (\% white) & 96.7 & 91.5 & 90.5 & $\chi^{2}=2.08$ & .35 \\
\hline Age (years) ${ }^{a}$ & $39.7(8.4)$ & $41.3(9.0)$ & $41.8(8.1)$ & $\hat{F}=0.62$ & .54 \\
\hline Marital status (\% married) & 39.3 & 49.2 & 46.0 & $\chi^{2}=1.23$ & .54 \\
\hline Education (years) ${ }^{a}$ & $14.1(2.6)$ & $13.8(2.4)$ & $13.9(2.0)$ & $\mathrm{F}=0.38$ & .68 \\
\hline Employment (\% full time) & 73.8 & 71.2 & 69.8 & $\chi^{2}=0.24$ & .89 \\
\hline \multicolumn{6}{|l|}{ Clinical features: } \\
\hline MAST score ${ }^{a, b}$ & $25.7(11.2)$ & $26.9(11.9)$ & $26.8(10.8)$ & $\mathrm{F}=0.20$ & .82 \\
\hline Family alcoholism index ${ }^{c}$ & $36.8(26.7)$ & $36.8(23.7)$ & $33.8(30.8)$ & $F=0.26$ & .77 \\
\hline \multicolumn{6}{|l|}{ Prior treatments for } \\
\hline alcoholism $^{a}$ & $1.0(2.6)$ & $1.0(1.3)$ & $1.4(4.0)$ & $\mathrm{F}=0.40$ & .67 \\
\hline BDI score ${ }^{a, d}$ & $1.9(3.2)$ & $1.7(2.3)$ & $2.2(3.7)$ & $\mathrm{F}=0.41$ & .67 \\
\hline
\end{tabular}

${ }^{a}$ Mean (SD)

${ }^{b}$ Michigan Alcoholism Screening Test (Selzer 1971).

${ }^{c}$ Percentage of $1^{\circ}$ relatives who are alcoholic.

${ }^{d}$ Beck Depression Inventory (Beck et al. 1961). 
vided information on alcoholism treatment history. The Michigan Alcoholism Screening Test (MAST; Selzer 1971) provided a lifetime measure of alcohol dependence and alcohol-related consequences.

Adverse Effects. Subjective reports of side effects were monitored weekly using a symptom checklist derived from the SAFTEE (Levine and Schooler 1986).

Collateral Information. At the time of enrollment in the study, the subject was asked to identify a collateral informant and for permission to contact the informant. At that time, and at the end of the treatment period, the informant was asked to complete a brief telephone interview regarding the subject's recent drinking behavior.

\section{Treatment}

All subjects received weekly coping skills training modeled after methods developed by McCrady et al. (1985) and Monti et al. (1986). The 12-session treatment consisted of a structured, manual-guided intervention designed to foster problem solving, interpersonal skills, relaxation, and skills for coping with cravings and urges. Subjects also learned to identify and handle situations that created a high risk for the resumption of drinking. Therapists used didactic presentations, behavioral rehearsal within sessions, and homework practice exercises for skills training.

Medication Conditions. All subjects underwent 1 week of single-blind, PLA treatment to identify those who were unlikely to be compliant with the study design. Subjects were then randomly assigned to receive NTX, NEF, or PLA for the remaining 11 weeks of the study. Because identical capsules were not available for the two medications, each subject took two different capsules daily. Each type of capsule contained one of the two active medications or a matching placebo. Subjects received only one of the active medications and one placebo, or a double placebo. The dosage of NTX was one capsule (i.e., $50 \mathrm{mg}$ ) daily. The dosage of NEF, which was initially one capsule (i.e., $100 \mathrm{mg}$ ) twice daily, was gradually increased to a target dosage of two capsules (i.e., $200 \mathrm{mg}$ ) twice daily. Among subjects who failed to respond to the medication (as evidenced by self-reports of continued heavy drinking), the dosage of NEF (or its matching PLA) was increased to a maximum of three capsules (i.e., $300 \mathrm{mg}$ ) twice daily.

Compliance. Riboflavin $25 \mathrm{mg}$ was included in the NTX and matching PLA capsules, making it possible to evaluate medication compliance for all subjects. Urine specimens were collected at each treatment visit and examined for the presence of riboflavin. The procedure used to evaluate the presence of urinary riboflavin by use of an ultraviolet light is detailed elsewhere (Del Boca et al. 1996). To avoid a source of the vitamin that may confound measurement in urine, subjects were provided with multivitamins that contained no riboflavin and were advised to use only that preparation.

\section{Statistical Analysis}

Analysis of variance (ANOVA), $\chi^{2}$, and the Fisher's Exact Test (two-tailed) were used to compare Medication Group on pretreatment measures. Bonferroni post hoc adjustment to $p$-values was made to reduce the risk of Type I error when pair-wise comparisons were made. Survival analysis and multiple regression analyses were used to determine the effect of the active medications on drinking behavior. A criterion of $p<.05$ was used to denote statistical significance.

Life table analysis was performed using weeks of study participation, number of weeks to the first drinking day, and number of weeks to the first heavy drinking day (defined as $\geqslant$ four drinks in a day for women and $\geqslant$ five drinks in a day for men) as dependent measures. The Wilcoxon (Gehan) test (Gehan 1965) served to determine the effect of group membership on these three measures. Pair-wise post hoc comparisons of each active medication with PLA were made using the Bonferroni adjustment.

Hierarchical multiple regression was used to examine three drinking measures: frequency (percentage of days drinking), average consumption (drinks per day), and heavy drinking (percentage of days on which the subject drank heavily) as dependent variables. Predictors were entered in logical order so that the unique effect of Medication Group could be assessed after controlling for pre-randomization (i.e., Pretreatment and Lead-in) levels of the respective variable and for Compliance.

In the regression analyses, Pretreatment drinking was entered as a continuous measure, and alcohol use during the Lead-in Period was coded dichotomously (abstinent, not abstinent) because of the bimodal distribution of subjects' drinking during that period. The next variable entered in these regression equations was Compliance, which was determined by the total number of urine samples (with a maximum of 12) that were positive for riboflavin. This variable accounts both for the duration of study participation and faithfulness to the medication regimen. That is, any subject who failed to attend the weekly sessions or take the medication would present fewer samples positive for riboflavin. The active medication conditions (NTX, NEF) were coded so that their effects could be contrasted with that of the PLA group. The interaction of Medication Group with Compliance was then entered into the equations. The technique of Johnson and Neyman (1936) was used to specify the nature of significant interactions. Predictors contributing minimally to explained variance were removed from the final analyses, freeing a like number of 
degrees of freedom and maximizing the analytic power of the equations. Cohen's effect sizes $\left(\mathrm{f}^{2}\right)$ were computed where statistical significance was found (Cohen 1988).

\section{Validation of Self-Reported Drinking}

Two methods were used to validate self-reported drinking. First, changes in GGTP level were correlated with changes in drinking variables. GGTP levels declined from 86.6 $\mathrm{U}(\mathrm{SD}=126.0 \mathrm{U})$ to $48.3 \mathrm{U}(\mathrm{SD}=64.8$ $\mathrm{U})$ for PLA-treated subjects, from $71.4 \mathrm{U}(\mathrm{SD}=80.0 \mathrm{U})$ to $47.4 \mathrm{U}(\mathrm{SD}=53.0 \mathrm{U}$ ) for NEF-treated subjects, and from 65.8 $\mathrm{U}(\mathrm{SD}=84.4 \mathrm{U})$ at Baseline to $42.7 \mathrm{U}(\mathrm{SD}=$ $72.5 \mathrm{U})$ at Treatment Endpoint for NTX-treated subjects. There were no significant between-group differences at Baseline $[\mathrm{F}(2,180)=0.72, p=.49]$ or Treatment Endpoint $[\mathrm{F}(2,152)=0.11, p=.90]$. Change in GGTP level over the course of treatment was modestly, but significantly, correlated with change in Percent Drinking Days $(\mathrm{r}=0.17, p=.033)$, and Average Intake $(\mathrm{r}=0.21$, $p=.010)$.

The second method of validating self-reported drinking measures used collateral informant reports. At Baseline, self-reported Percent Drinking Days ( $r=0.60$, $p<.001)$, and Percent Heavy Drinking Days ( $\mathrm{r}=0.41$, $p<.001$ ) were moderately, and significantly, correlated with the respective measures from collateral reports. Moderate, significant associations were also observed for these measures at Treatment Endpoint $(\mathrm{r}=0.67, p<$ $.001 ; \mathrm{r}=0.59, p=.001$, respectively).

In summary, collateral informant reports, and to a lesser degree GGTP levels, provided evidence for the validity of self-reports concerning drinking behavior by study subjects.

\section{RESULTS}

\section{Subject Retention}

As shown in Figure 1, of the 183 subjects who were randomly assigned to treatment, 129 (70.5\%) completed the 11-week Randomized Treatment Period. This included $79.4 \%$ of PLA subjects, $72.9 \%$ of NEF subjects, and $59.0 \%$ of NTX subjects. Survival analysis yielded a significant group difference [Wilcoxon $($ Gehan $)=7.61$, $p=.022]$. A pair-wise comparison revealed that the NTX group had a significantly lower rate of retention than the PLA group (Bonferroni-adjusted $p=.008$ ); the pair-wise comparison of the NTX and NEF groups did not reach significance $(p=.067)$.

\section{Medication Dosage and Tolerance}

Although all subjects in the NTX group received 50 $\mathrm{mg}$ / day of that medication, dosage of NEF could vary; the mean maximal dosage of NEF was 418.6 (SD =

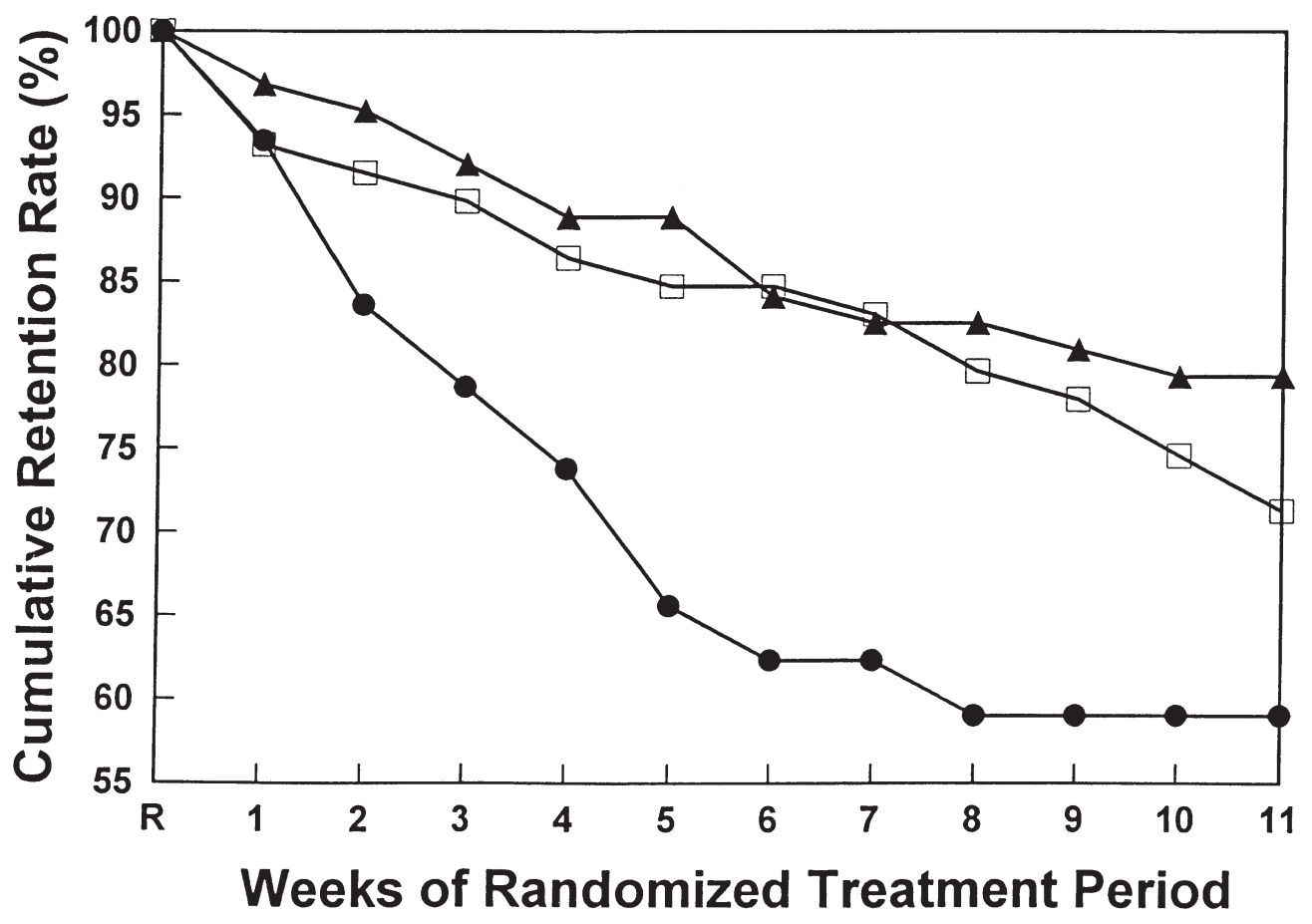

Figure 1. Cumulative rate of retention in treatment. Naltrexone $[n=61](-\bullet-)$, Nefazodone $[n=59](-\square-)$, and Placebo $[n=$ 63] (- $\mathbf{\Delta}-)$. Wilcoxon (Gehan) statistic $=7.61, p=.022)$. Pair-wise comparisons revealed that the Naltrexone group had a significantly lower rate of retention than the Placebo group (Bonferroni-adjusted $p=.008$ ). For the Naltrexone-Nefazadone pair-wise comparison the Bonferroni-adjusted $p=.067$. 
119.6) $\mathrm{mg} /$ day. Comparisons between the number of capsules of each of the active medications and the number of matching PLA capsules that the other two medication groups received showed no between-group differences ( $p$ s all $>.10)$.

The percentage of subjects by Medication Group that reported specific adverse effects is shown in Table 2. Compared with the PLA group, NEF-treated subjects were significantly more likely to report having experienced blurred vision, dizziness, and lightheadedness. NTX-treated subjects were significantly more likely to report having had blurred vision, drowsiness, lightheadedness, poor coordination, confusion, decreased appetite, nausea, and vomiting than subjects receiving PLA. When the mean number of adverse effects was examined on a week-by-week basis, significant group differences were noted at the first $[\mathrm{F}(2,180)=7.44, p=$ $.001]$, fifth $[\mathrm{F}(2,180)=3.99, p=.020]$, and eighth $[\mathrm{F}(2,158)=5.74, p=.004]$ weeks of the Randomized Treatment Period. In each instance, NTX-treated subjects reported a significantly greater number of adverse events than the PLA group (Bonferroni-adjusted $p=.003$, $p=.049$, and $p=.004$ for weeks 1,5 , and 8 , respectively).

\section{Treatment Compliance}

Compliance (i.e., the total number of urine samples positive for riboflavin, to a maximum of 12) also dif- fered by Medication Group $[\mathrm{F}(2,180)=4.04, p=.019]$. The PLA group had $79.8 \%$ of urine tests positive for riboflavin, as compared with $76.8 \%$ for the NEF group and $66.0 \%$ for the NTX group. The only significant pairwise difference was between the NTX and PLA groups (Bonferroni-adjusted $p=.022$ ).

When examined on a week-by-week basis, the rate of compliance for the NTX group was significantly lower than that of the other two groups ( $p$ s < .05) at weeks 3, 7, and 10 postrandomization (see Figure 2). There was no difference in compliance between the PLA and NEF groups. Subsequent to week 3, as few as 29 NTX subjects (47.5\%) presented urine samples that were positive for riboflavin. Interestingly, the pattern of poorer compliance among NTX subjects is similar to that for adverse effects, except that it lags 2 weeks behind the pattern of adverse events. This suggests that increases in adverse events in the NTX group were followed 2 weeks later by decreases in compliance in this group. This, in turn, was followed by early discontinuation of study participation.

\section{Integrity of the Double Blind}

Because subjects were asked to judge which treatment they thought they received, it was possible to determine whether the blind had been penetrated. Overall, $58.0 \%$ of subjects were able to differentiate active (NTX or NEF) correctly from PLA treatment, including $41.0 \%$ of

Table 2. Adverse Effects by Medication Group

\begin{tabular}{lrcc}
\hline & Placebo $(\boldsymbol{n}=\mathbf{6 3})$ & Nefazodone $(\boldsymbol{n}=\mathbf{5 9 )}$ & Naltrexone $(\boldsymbol{n}=\mathbf{6 1})$ \\
\hline Any neuropsychiatric & & & \\
$\quad$ symptom & 68.9 & 84.7 & 86.9 \\
Blurred vision & 3.2 & $18.6^{b}$ & $16.4^{b}$ \\
Dizziness & 12.7 & $32.2^{b}$ & 26.2 \\
Drowsiness & 36.5 & 45.8 & $62.3^{b}$ \\
Headache & 46.0 & 50.8 & 45.9 \\
Lightheadedness & 14.3 & $33.9^{b}$ & $44.3^{b}$ \\
Weakness & 69.8 & 84.7 & 86.9 \\
Poor coordination & 1.6 & 10.2 & $16.4^{b}$ \\
Insomnia & 39.7 & 35.6 & 59.0 \\
Fatigue & 52.4 & 64.4 & 59.0 \\
Confusion & 7.9 & 22.0 & $26.2^{b}$ \\
Sleepiness & 38.1 & 47.5 & 47.5 \\
Any gastrointestinal & & & $77.1^{b}$ \\
$\quad$ symptom & 52.4 & 59.3 & 39.3 \\
Dry mouth & 31.7 & 35.6 & $37.7^{b}$ \\
Decreased appetite & 14.3 & 15.3 & $32.8^{b}$ \\
Nausea & 14.3 & 25.4 & $19.7^{b}$ \\
Vomiting & 4.8 & 16.9 & 29.5 \\
Stomach pain & 12.7 & 16.9 & 26.2 \\
Constipation & 15.9 & 23.7 & 34.4 \\
Diarrhea & 20.6 & 28.8 & 90.2 \\
Any symptom & 81.0 & 88.1 & \\
Do & & & \\
\hline
\end{tabular}

${ }^{a}$ Percentage of subjects reporting $\geqslant 1$ adverse event during the 11-week Randomized Treatment Period.

${ }^{b} p<.05$ vs. Placebo [ $\chi^{2}(1 \mathrm{df})$, Bonferroni adjusted]. 


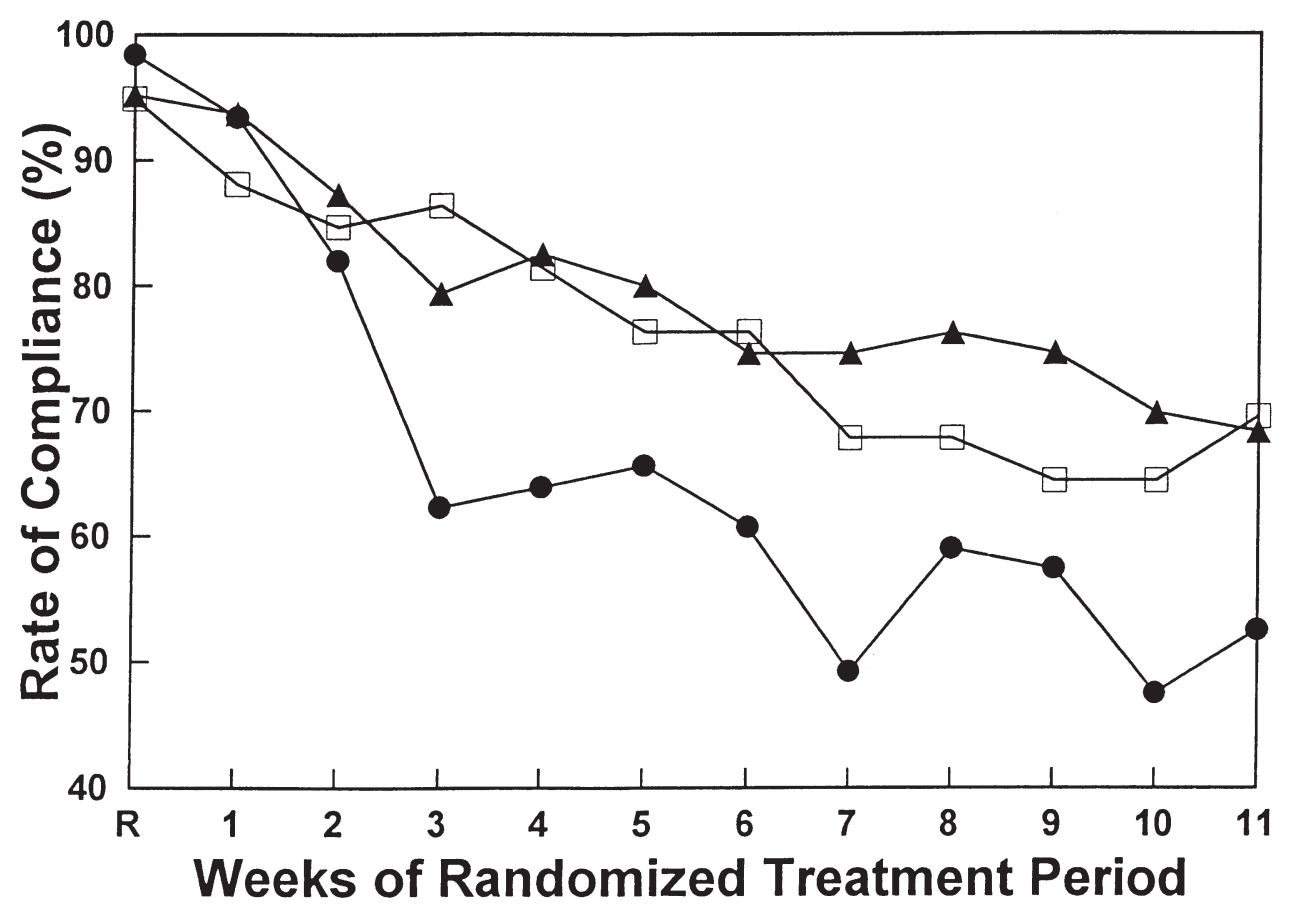

Figure 2. Rate of medication compliance. Compliance measured by the presence of urinary riboflavin at each week of the randomized treatment period. Naltrexone $[n=61](-\mathbf{-}-)$, Nefazodone $[n=59](-\square-)$ and Placebo $[n=63](-\mathbf{\Delta}-)$. Beginning at week 3 of the randomized treatment period, the rate of compliance of the Naltrexone group was significantly lower than that of the other two groups (ps <.05).

PLA subjects, $74.5 \%$ of NEF subjects, and $60.3 \%$ of NTX subjects $\left[\chi^{2}(2)=3.66, p=.16\right]$.

\section{Effects of Medication on Alcohol Consumption}

Abstinence Rates, Time to First Drink and Time to First Heavy Drinking Episode. Fifty-nine subjects (32.2\%) achieved total abstinence from alcohol during the 11-week treatment period $(\mathrm{PLA}=34.9 \%, \mathrm{NEF}=32.2 \%$, and NTX $=$ $29.5 \%$, a nonsignificant difference). There also were no differences on time to first drink as a function of Medication Group. PLA subjects consumed their first drink a mean of $5.7(\mathrm{SD}=4.5)$ weeks after randomization, as compared to 5.3 $(\mathrm{SD}=4.6)$ weeks for NEF subjects and $6.0(\mathrm{SD}=4.7)$ weeks for NTX subjects [Wilcoxon (Gehan) $=0.99, p=.61$ ]

As shown in Figure 3, time to first heavy drinking episode (i.e., consumption of $\geqslant$ four standard drinks for women and $\geqslant$ five standard drinks for men) also did not differ by Medication Group [Wilcoxon (Gehan) = $0.35, p=.84]$. The mean for the PLA group on this measure was $8.0(\mathrm{SD}=4.0)$ weeks and for both the NTX and NEF groups the mean was $7.2(\mathrm{SD}=4.6)$ weeks.

Continuous Measures of Alcohol Consumption. Continuous measures of alcohol consumption during the Pretreatment and Randomized Treatment Periods are shown in Table 3, along with univariate statistical comparisons based on Medication Group. In the paragraphs that follow, however, the statistical comparisons based on Medication Group are those that control for other relevant predictor variables using multiple regression analysis.

DRINKING FREQUENCY. Frequency of drinking during the Pretreatment Period was positively correlated with Drinking Frequency during the Randomized Treatment Period $\left[\beta=0.216, \mathrm{~F}(1,180)=8.78, p=.003, \mathrm{f}^{2}=\right.$ $0.046]$ and negatively correlated with abstinence during the PLA Lead-in Period $[\beta=-0.454, \mathrm{~F}(1,179)=49.44, p<$ $\left..001, \mathrm{f}^{2}=0.216\right]$. Subjects who were more compliant with treatment drank on fewer occasions $[\beta=-0.352, \mathrm{~F}$ $\left.(1,178)=33.17, p<.001, \mathrm{f}^{2}=0.157\right]$. However, neither of the active medication groups differed from PLAtreated subjects on drinking frequency [NTX: $\beta=0.014$, $\mathrm{F}(1,177)=0.05, p=.82$; NEF: $\beta=-0.081, \mathrm{~F}(1,176)=$ $1.32, p=.25]$. The interaction of Medication Group and Compliance was also not significant $(p>.10)$

Average DrinKING LeVEL. Mean Number of Drinks Per Day during the Randomized Treatment Period was also positively correlated with its respective pretreatment measure $\left[\beta=0.191, \mathrm{~F}(1,180)=6.79, p=.010, \mathrm{f}^{2}=0.036\right]$ and negatively correlated with abstinence during the PLA Lead-in Period $[\beta=-0.419, \mathrm{~F}(1,179)=39.43, p<.001$, $\left.\mathrm{f}^{2}=0.181\right]$. Subjects who were more compliant with treatment also reported lower mean drinking levels $[\beta=$ $\left.-0.365, \mathrm{~F}(1,178)=33.36, p<.001, \mathrm{f}^{2}=0.158\right]$. However, neither of the active medication groups differed from PLAtreated subjects on average drinking level [NTX: $\beta=0.046$, 


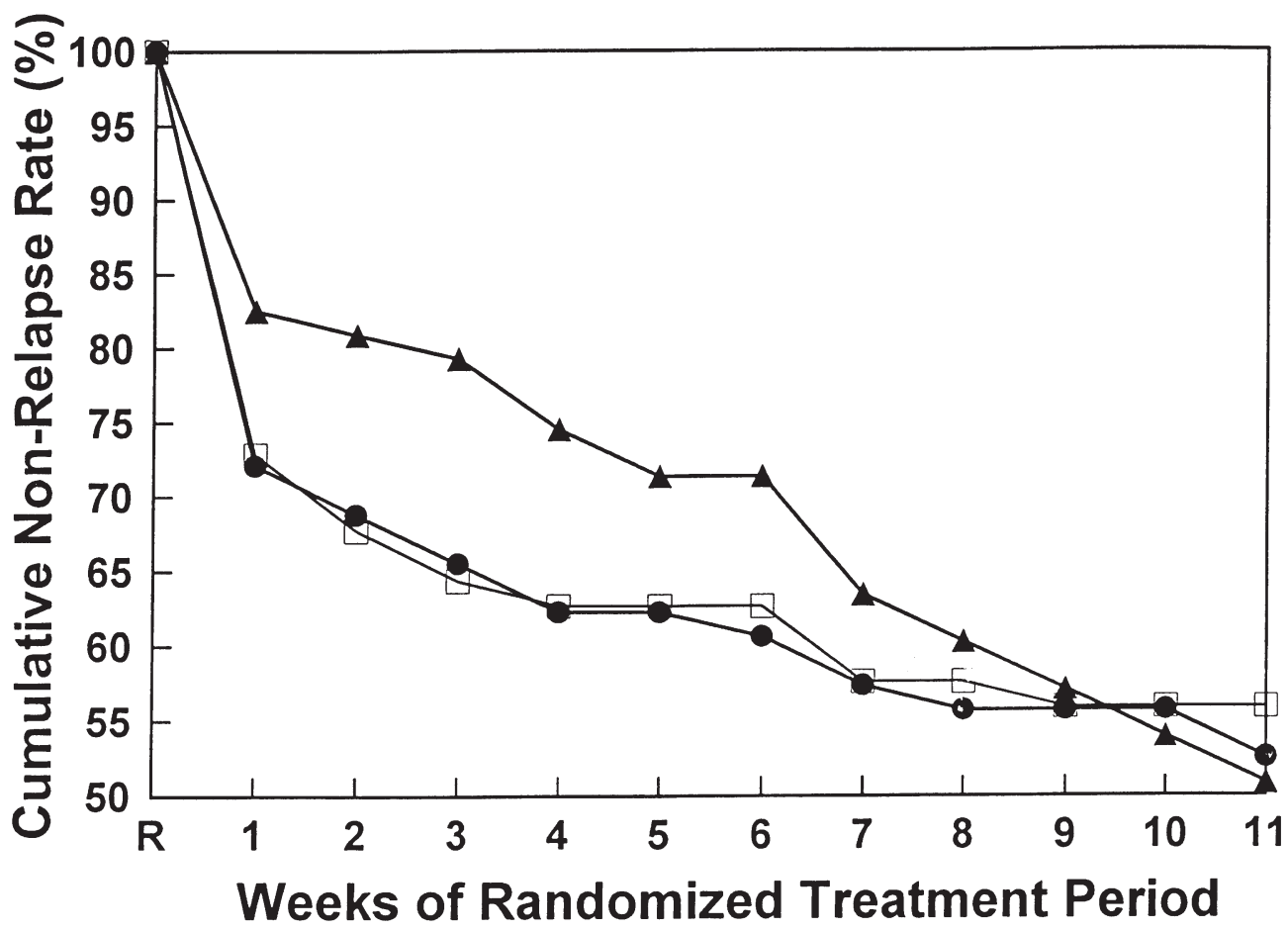

Figure 3. Rate of relapse to heavy drinking. Heavy drinking defined as $\geqslant$ five drinks a day for males and $\geqslant$ four drinks a day for females. Naltrexone $[n=61](-\mathbf{-})$, Nefazodone $[n=59](-\square-)$ and Placebo $[n=63](-\boldsymbol{\Delta}-)$. There were no significant between-group differences observed [Wilcoxon (Gehan) statistic $=0.35, p=0.84)]$.

$\mathrm{F}(1,177)=0.55, p=.46 ; \mathrm{NEF}: \beta=0.018, \mathrm{~F}(1,176)=0.06$, $p=.81]$. Of the interactions, only the Compliance $\times \mathrm{NEF}$ interaction achieved statistical significance $[\beta=-0.171$, $\left.\mathrm{F}(1,174)=6.32, p=0.013, \mathrm{f}^{2}=0.035\right]$. However, further examination revealed that the effect was attributable to the inclusion of two subjects with particularly high drinking levels, the removal of whom rendered the analysis nonsignificant $[\beta=-0.012, \mathrm{~F}(1,172)=0.026, p=.87]$.

FREQUENCY OF HEAVY DRINKING. The frequency of heavy drinking during the Pretreatment Period was significantly correlated with the comparable measure during the Randomized Treatment Period $[\beta=0.245, \mathrm{~F}$ $\left.(1,180)=11.47, p=.001, \mathrm{f}^{2}=0.060\right]$, as was abstinence during the PLA Lead-in Period $[\beta=-0.347, \mathrm{~F}(1,179)=$ 26.26, $p<.001, \mathrm{f}^{2}=0.128$ ]. Subjects who were more compliant had lower frequency of heavy drinking $[\beta=$ $\left.-0.305, \mathrm{~F}(1,178)=21.41, p<.001, \mathrm{f}^{2}=0.107\right]$. Once again, neither of the active medication groups differed

Table 3. Measures of Alcohol Consumption by Medication Group ${ }^{a}$

\begin{tabular}{|c|c|c|c|c|c|}
\hline & Naltrexone $(n=60)$ & Nefazodone $(n=59)$ & Placebo $(n=63)$ & Test & $p$ \\
\hline \multicolumn{6}{|l|}{ Pretreatment period $^{b}$} \\
\hline Drinking days (\%) & $72.0(21.7)$ & 75.3 (20.6) & 69.9 (23.1) & $\mathrm{F}=0.95$ & .39 \\
\hline Average drinks & $7.7(4.3)$ & $7.2(4.5)$ & $7.2(4.5)$ & $\mathrm{F}=0.34$ & .71 \\
\hline Heavy drinking days $(\%)^{c}$ & $64.8(24.7)$ & $63.3(27.3)$ & $59.1(29.6)$ & $\mathrm{F}=0.73$ & .48 \\
\hline OCDS score $\mathrm{e}^{d}$ & $17.2(5.6)$ & $16.5(5.4)$ & $17.4(12.0)$ & $F=0.26$ & .81 \\
\hline \multicolumn{6}{|l|}{ Randomized treatment period ${ }^{e}$} \\
\hline Drinking days (\%) & $21.2(28.9)$ & $16.8(23.1)$ & $15.7(21.3)$ & $\mathrm{F}=0.90$ & .43 \\
\hline Average drinks & $1.4(2.1)$ & $1.2(2.3)$ & $.81(1.3)$ & $\mathrm{F}=1.48$ & .23 \\
\hline Heavy drinking days $(\%)^{c}$ & $12.4(21.4)$ & $11.1(23.0)$ & $7.8(16.3)$ & $\mathrm{F}=0.90$ & .43 \\
\hline OCDS Score ${ }^{d}$ & $8.4(5.7)$ & $6.8(5.6)$ & $7.5(5.0)$ & $\mathrm{F}=1.23$ & .29 \\
\hline
\end{tabular}

${ }^{a}$ All values are mean (SD).

$b$ 90-day period.

${ }^{c}$ For females $\geqslant$ four drinks in a day; for males $\geqslant 5$ drinks in a day.

${ }^{d}$ Obsessive Compulsive Drinking Scale (Anton et al. 1995).

e 77- day period. 
from PLA-treated subjects on frequency of heavy drinking [NTX: $\beta=0.014, \mathrm{~F}(1,177)=0.04, p=.84 ; \mathrm{NEF}: \beta=$ $0.013, \mathrm{~F}(1,176)=0.03, p=.86]$. The only other effect that achieved significance was the interaction of compliance X NEF $\left[\beta=-0.143, \mathrm{~F}(1,174)=3.94, p=.049, \mathrm{f}^{2}=\right.$ 0.022]. As was true for average drinking level, removal from the analysis of the two individuals referred to above rendered the statistic nonsignificant $[\beta=-0.014$, $\mathrm{F}(1,172)=0.03, p=.86]$.

\section{DISCUSSION}

This study is the first controlled trial in alcoholics in which the opioid antagonist NTX was compared with both an inactive PLA and an active pharmacological agent. The results failed to provide evidence of the superiority of either active agent over PLA in preventing or moderating relapse to heavy drinking. These findings are in contrast to the initial reports of NTX's efficacy in the treatment of alcohol dependence $\left(\mathrm{O}^{\prime}\right.$ Malley et al. 1992; Volpicelli et al. 1992). Subsequent to those reports, however, Volpicelli et al. (1997) found no advantage for NTX in an intention-to-treat analysis. In that study, only highly compliant alcoholics showed an advantage of NTX over PLA, with the active drug reducing risk for drinking and relapse and total drinks consumed. In a study of a sustained-release NTX formulation (Kranzler et al. 1998), only subjects who tolerated the medication when it was administered orally (i.e., $61 \%$ of those entering the oral treatment phase) received the depot injection. However, among subjects who tolerated the oral medication and went on to receive an injection, depot NTX showed a moderate-to-large treatment effect, particularly on the frequency of heavy drinking.

In the present study, subjects who were more compliant with treatment showed greater reductions in the frequency of drinking and heavy drinking and in average alcohol consumption. Furthermore, subjects who were compliant with NEF treatment showed greater improvement on both average drinking and frequency of heavy drinking. However, these latter effects seemed to be spurious, because the presence in the NEF group of two particularly heavy-drinking subjects who showed improvement during treatment seems to have disproportionately affected the results. When these subjects were removed from the analysis, the effects were no longer present. Despite evidence that NEF reduces alcohol consumption in a rodent model (Olausson et al. 1998), a recent study in depressed alcoholics showed that, although NEF was efficacious in reducing depressive symptoms, it did not reduce drinking behavior (Roy-Byrne et al. 2000).

NTX-treated subjects reported more adverse effects and showed poorer treatment retention and a lower rate of medication compliance than PLA-treated subjects, all of which may have obscured a potential therapeutic advantage of the active medication by substantially reducing the statistical power of the study. Gastrointestinal adverse events were particularly common in NTX-treated subjects. In fact, analysis revealed that subjects who reported more GI adverse events during the Pretreatment period were significantly more susceptible to subsequent GI adverse events when treated with NTX (data not shown). Furthermore, these effects increased when compliance was controlled: the more faithfully NTX-treated subjects complied with the medication regimen, the greater the number of GI adverse events they reported (data not shown). These findings suggest that the clinical utility of NTX is limited, particularly among subjects who, before the initiation of treatment, have GI complaints.

Initial controlled studies of NTX in alcoholics (O'Malley et al. 1992; Volpicelli et al. 1992) showed a relatively low frequency of adverse effects and consequent study discontinuation. An open-label safety study of NTX in 570 alcohol-dependent patients (Croop et al. 1997) showed the most common new onset adverse clinical events to be nausea $(9.8 \%)$ and headache $(6.6 \%)$. In that study, NTX treatment was discontinued in $15.0 \%$ of patients because of adverse events, most frequently nausea. However, studies of former opioid addicts (Crowley et al. 1985), normal control subjects (Swift et al. 1994, Mendelson et al. 1979), and heavy drinkers (Davidson et al. 1999) have shown the drug to produce substantial rates of both neuropsychiatric and gastrointestinal adverse effects. Overall, it seems that, irrespective of diagnosis, there are substantial numbers of individuals who experience dysphoria, nausea, and other poorly tolerated adverse effects of opioid blockade.

This finding underscores the need for research to identify features that underlie NTX tolerability. O'Malley et al. (2000) examined predictors of NTX-induced nausea in 120 alcoholics treated with $50 \mathrm{mg} /$ day of the medication. In that study, 10 subjects $(8.5 \%)$ reported having had mild nausea, and 18 individuals (15\%) experienced moderateto-severe nausea (with eight individuals discontinuing the medication). Subjects with moderate-to-severe nausea were less likely to comply with the medication regimen and were more likely to drink heavily than were other study participants. Variables that predicted the presence of moderate-to-severe nausea included younger age, female gender, and a shorter period of abstinence and lower level of daily alcohol consumption before beginning NTX. In addition, there was a significant interactive effect of alcohol consumption, such that lighter drinkers had a greater risk of nausea at a shorter duration of abstinence.

Additional research on individual responses to the effects of NTX may help to determine the relative importance of decreased craving for alcohol, decreased positive reinforcement induced by drinking, and aversive effects of the medication in reducing the risk of alcoholic relapse (Davidson et al. 1999). Clinically, such information may 
also help in the development of methods to enhance patients' capacity to tolerate the medication. We initiated NTX treatment at a dosage of $50 \mathrm{mg} /$ day based on the FDA approval of that dosage, which was the dosage used in the initial studies of the medication in alcoholics. The use of a lower initial dosage of NTX with gradual increases might reduce adverse effects and enhance compliance and study retention; such an approach has greater clinical validity. However, such practices as this, as well as the use of adjunctive medications to reduce adverse effects, require controlled evaluation. Comparative studies involving other opioid antagonists, such as nalmefene (Mason et al. 1999), are also needed to determine whether such medications are better tolerated than NTX. Factors that influence the acceptability of a medication by alcoholics are important in the development of medications suitable for widespread use in this patient population.

\section{ACKNOWLEDGMENT}

This study was supported by NIH Grants P50-AA03510, T32AA07290, K02-AA00239 (HRK) and M01-RR06192 (General Clinical Research Center of the University of Connecticut School of Medicine). The authors thank the staff of the Clinical Research and Evaluation Unit, particularly Roberta Gline and Kitzia Skipsey, for their assistance in the conduct of this study and Ola Blomqvist, M.D., Ph.D. and Helen Pettinati, Ph.D. for their helpful comments on the manuscript.

\section{REFERENCES}

Aguirre JC, Del Arbol JL, Raya J, Ruiz-Requena ME, Irles JR (1990): Plasma beta-endorphin levels in chronic alcoholics. Alcohol 7:409-412

American Psychiatric Association (1987): Diagnostic and Statistical Manual of Mental Disorders, 3rd Ed. rev. Washington DC, American Psychiatric Press

Anton RF, Moak DH, Latham PK (1995): The obsessive compulsive drinking scale: A self-rated instrument for the quantification of thoughts about alcohol and drinking behavior. Alcohol Clin Exp Res 1:92-99

Banki C (1981): Factors influencing monoamine metabolites and tryptophan in patients with alcohol dependence. J Neural Trans 50:98-101

Beck AT, Ward CH, Mendelson M, Mock J, Erbaugh J (1961): An inventory for measuring depression. Arch Gen Psychiat 4:461-471

Cohen J (1988): Statistical Power Analysis for the Behavioral Sciences, 2nd Ed. Hillsdale NJ, Lawrence Erlbaum Associates

Croop RS, Faulkner EB, Labriola DF (1997): The safety profile of naltrexone in the treatment of alcoholism. Results from a multicenter usage study. The Naltrexone Usage Study Group. Arch Gen Psychiat 54:1130-1135

Crowley TJ, Wagner JE, Zerbe G, Macdonald M (1985): Naltrexone-induced dysphoria in former opioid addicts. Am J Psychiat 142:1081-1084
Davidson D, Palfai T, Bird C, Swift R (1999): Effects of naltrxone on alcohol self-adminstration in heavy drinkers. Alcohol Clin Exp Res 23:195-203

Del Boca FK, Kranzler HR, Brown J, Korner P (1996): Assessment of medication compliance in alcoholics through UV light detection of a riboflavin tracer. Alcohol Clin Exp Res 20:1412-1417

Gehan EA (1965): A generalized Wilcoxon test for comparing arbitrarily singly censored samples. Biometrika 52:203-223

Genazzani A, Nappi G, Facchinetti F, Mazzella GL, Parrini D, Sinforiani E, Petaraglia F, Savoldi F (1981): Central deficiency of beta-endorphin in alcohol addicts. J Clin Endocrinol Metab 55:583-586

Gerra G, Caccavari R, Delsignore R, Bocchi R, Fertonani G, Passeri M (1992): Effects of fluoxetine and Ca-acetylhomotaurinate on alcohol intake in familial and nonfamilial alcohol patients. Curr Therapeut Res 52:291-295

Gianoulakis C, Beliveau D, Angelogianni P, Meaney M, Thavundayil J, Tawar V, Duams M. (1989): Different pituitary beta-endorphin and adrenal cortisol response to ethanol in individuals with high and low risk for future development of alcoholism. Life Sci 45:1097-1109

Gianoulakis C, Krishnan B, Thavundayil J (1996): Enhanced sensitivity of pituitary $\beta$-endorphin to ethanol in subjects at high risk of alcoholism. Arch Gen Psychiat 53:250-257

Gorelick DA (1989): Serotonin uptake blockers and the treatment of alcoholism. In Galanter M (ed), Recent Developments in Alcoholism, Vol. 7

Gorelick DA, Paredes A (1992): Effect of fluoxetine on alcohol consumption in male alcoholics. Alcohol Clin Exp Res 16:261-265

Hersh D, Van Kirk JR, Kranzler HR (1998): Naltrexone treatment of comorbid alcohol and cocaine use disorders. Psychopharmacology 139:44-52

Hesselbrock M, Babor TF, Hesselbrock V, Meyer RE, Workman K (1983): Never believe an alcoholic? On the validity of self-report measures of alcohol dependence and related constructs. Int J Addict 18:593-609

Johnson PO, Neyman J (1936): Tests of certain linear hypotheses and their application to some educational problems. Statist Res Memoirs 1:57-93

Kabel DI, Petty F (1996): A double blind study of fluoxetine in severe alcohol dependence: Adjunctive therapy during and after inpatient treatment. Alcohol Clin Exp Res 20:780-784

Kranzler HR, Burleson JA, Korner P, Del Boca FK, Bohn MJ, Brown J, Liebowitz N (1995): Placebo-controlled trial of fluoxetine as an adjunct to relapse prevention in alcoholics. Am J Psychiat 152:391-397

Kranzler HR, Del Boca F, Korner P, Brown J (1993): Adverse effects limit the usefulness of fluvoxamine for the treatment of alcoholism. J Subst Abuse Treat 10:283-287

Kranzler HR, Jaffe JH (1998): Medications for use in alcoholism rehabilitation. In Graham AW, Schultz TK (eds), Principles of Addiction Medicine, 2nd ed. Chevy Chase, MD, American Society of Addiction Medicine, pp 501-516

Kranzler HR, Modesto-Lowe V, Nuwayser ES (1998): A sustained-release naltrexone preparation for treatment of alcohol dependence. Alcohol Clin Exp Res 22:1074-1079

Levine J, Schooler NR (1986): SAFTEE: A technique for the 
systematic assessment of side effects in clinical trials. Psychopharmacol Bull 22:343-381

Litten RZ, Allen J (1998): Advances in development of medications for alcoholism treatment. Psychopharmacology 139:20-33

Mason BJ, Salvato FR, Williams LD, Ritvo EC, Cutler RB (1999): A double-blind, placebo-controlled study of oral nalmefene for alcohol dependence. Arch Gen Psychiat 56:719-24

McCrady BS, Dean L, DuBreuil E, Swanson S (1985): The problem drinkers project: A programmatic application of social learning-based treatment. In Marlatt GA, Gordon JR (eds), Relapse Prevention: Maintenance Strategies in the Treatment of Addictive Behaviors. New York, Guilford Press, pp 417-471

Meert TF, Awouters F, Niemegeers CJE, Schellekens KHL, Janssen PAJ (1991): Ritanserin reduces abuse of alcohol, cocaine, and fentanyl in rats. Pharmacopsychiatry 24:159-163

Mendelson JH, Ellingboe J, Keuhnle JC, Mello NK (1979): Effects of naltrexone on mood and neuroendocrine function in normal adult males. Psychoneuroendocrinology 3:231-236

Monti PM, Abrams DB, Binkoff JA, Zwick WR (1986): Interpersonal skills and substance abuse: Theoretical and practical considerations. In Hollin CR, Trower P (eds), Handbook of Social Skills Training: Clinical Applications and New Directions. New York, Pergamon

Myers RD, Lankford M, Bjork A (1993): 5-HT2 receptor blockade by amperozide suppresses ethanol drinking in genetically preferring rats. Pharmacol Biochem Behav 45:741-747

Naranjo CA, Kadlec KE, Sanhueza P, Woodley-Remus D, Sellers EM (1990): Fluoxetine differentially alters alcohol intake and other consummatory behaviors in problem drinkers. Clin Pharmacol Ther 47:490-498

Naranjo CA, Poulos CX, Bremner KE, Lanctot KL (1994): Fluoxetine attenuates alcohol intake and desire to drink. Int Clin Psychopharmacol 9:163-172

Naranjo CA, Sellers EM, Roach CA, Woodley DV, SanchezCraig M, Sykora K (1984): Zimelidine-induced variations in alcohol intake by nondepressed heavy drinkers. Clin Pharmacol Ther 35:374-381

Naranjo CA, Sellers EM, Sullivan JT, Woodley DV, Kadlec K, Sykora K (1987): The serotonin uptake inhibitor citalopram attenuates ethanol intake. Clin Pharmacol Ther 41:266-274

Naranjo CA, Sullivan JT, Kadlec KE, Woodley-Remus DV, Kennedy G, Sellers EM (1989): Differential effects of viqualine on alcohol intake and other consummatory behaviors. Clin Pharmacol Ther 46:301-309

Olausson P, Ericson M, Petersson A, Kosowski A, Soderpalm B, Engel JA (1998): Nefazodone attenuates the behavioral and neurochemical effects of ethanol. Alcohol 15:77-86

O'Malley SS, Jaffe AJ, Chang G, Schottenfeld RS, Meyer RE, Rounsaville B (1992): Naltrexone and coping skills ther- apy for alcohol dependence: A controlled study. Arch Gen Psychiat 49:894-898

O'Malley SS, Krishnan-Sarin S, Farren C, O'Connor PG (2000): Naltrexone- induced nausea in patients treated for alcohol dependence: Clinical predictors and evidence for opioid mediated effects. J Clin Psychopharmacol, in press

Oslin D, Liberto JG, O’Brien J, Krois S, Norbeck J (1997): Naltrexone as an adjunctive treatment for older patients with alcohol dependence. Am J Geriatr Psychiat 5:324332

Roy A, Virkkunen M, Linnoila M (1990): Serotonin in suicide, violence, and alcoholism. In Coccaro EF, Murphy DL (eds), Serotonin in Major Psychiatric Disorders. Washington, DC: American Psychiatric Press

Roy-Byrne P, Pages KP, Russo JE, Blume AW, Jaffe C, Kingsley E, Cowley DS, Ries RK (2000): A double-blind placebo-controlled trial of nefazodone in the treatment of major depression in alcohol dependent patients. J Clin Psychopharmacol, in press

Selzer ML (1971): The Michigan Alcoholism Screening Test: The quest for a new diagnostic instrument. Am J Psychiat 127:1653-1658

Sobell LC, Maisto SA, Sobell MB, Cooper AM (1979): Reliability of alcohol abusers' self-reports of drinking behavior. Behav Res Ther 17:157-160

Sobell MB, Maisto SA, Sobell LC, Cooper AM, Cooper TC, Sanders B (1980): Developing a prototype for evaluating alcohol treatment effectiveness. In Sobell LC, Sobell MB, Ward E (eds), Evaluating Alcohol and Drug Abuse Treatment Effectiveness: Recent Advances. New York, Pergamon Press

Sobell MB, Sobell LC, Klajner F, Pavan D, Basian E (1986): The reliability of a timeline method for assessing normal drinker college students' recent drinking history: Utility for alcoholic research addict behav 11:149-161

Spitzer RL, Williams JBW, Gibbon M, First MB (1992): The Structured Clinical Interview for DSM-III-R. I. History, rationale, and description. Arch Gen Psychiat 49:624629

Swift RM, Whelihan W, Kuznetsov O, Buongiorno G, Hsuing H (1994): Naltrexone-induced alterations in human ethanol intoxication. Am J Psychiat 151:1463-1467

Taylor DP, Carter RB, Eison AS, Mullins UL, Smith HL, Torrente JR, Wright RN, Yocca FD (1995): Pharmacology and neurochemistry of nefazodone, a novel antidepressant drug. J Clin Psychiat 56:3-11

Volpicelli J, Rhines KC, Rhines JS, Volpicelli LA, Alterman AI, O'Brien CP (1997): Naltrexone and alcohol dependence: Role of subject compliance. Arch Gen Psychiat 54:737-742

Volpicelli JR, Alterman AI, Hayashida M, O'Brien C (1992): Naltrexone and the treatment of alcohol dependence. Arch Gen Psychiat 49:876-880 